\title{
Imaging of Carpal Instabilities
}

\section{Bildgebende Diagnostik karpaler Instabilitäten}

Authors

Jan-Peter Grunz, Carsten Herbert Gietzen, Katharina Grunz, Thorsten Bley, Rainer Schmitt

Affiliation

Department of Diagnostic and Interventional Radiology, University Hospital Würzburg, Germany

Key words

arthrography, hand, radiography, MR imaging

received 11.02.2020

accepted 13.07.2020

published online 03.09.2020

Bibliography

Fortschr Röntgenstr 2021; 193: 139-150

DOI 10.1055/a-1219-8158

ISSN 1438-9029

(c) 2020. Thieme. All rights reserved.

Georg Thieme Verlag KG, Rüdigerstraße 14,

70469 Stuttgart, Germany

Correspondence

Dr. Jan-Peter Grunz

Department of Diagnostic and Interventional Radiology,

University Hospital Würzburg, Oberdürrbacher Straße 6,

97080 Würzburg, Germany

Tel.: +4993120134001

Grunz_J@ukw.de

\section{ZUSAMMENFASSUNG}

Hintergrund Karpale Instabilität bezeichnet verschiedene Formen von Handgelenkbeschwerden, bei denen die Handwurzel ihren physiologischen Bewegungsumfang einbüßt und die normale Kraftübertragung auf den Unterarm bzw. die Metacarpalia nicht aufrechterhalten werden kann. Je nach Ursache und Pathoanatomie werden 4 Hauptgruppen unterschieden: dissoziative, nicht dissoziative, komplexe und adaptive karpale Instabilität. Dabei machen dissoziative Gefügestörungen den größten Anteil aus. Sie werden weiter unterteilt entsprechend der zugrunde liegenden karpalen Bandverletzung und der resultierenden dorsalen oder palmaren Fehlstellung der mittleren karpalen Säule.

Methode Dieser Übersichtsartikel beschreibt die verschiedenen Formen karpaler Instabilität, ihre Pathophysiologie und typische klinische Beschwerden. Darüber hinaus werden die diagnostische Bedeutung verschiedener bildgebender Verfahren sowie die etablierten Behandlungsmöglichkeiten im Kontext der aktuellen Literatur diskutiert.
Ergebnisse und Schlussfolgerung Die frühzeitige Erkennung und Behandlung von karpalen Gefügestörungen ist unerlässlich, um einer progredienten Arthrose vorzubeugen. Traumatische Läsionen des skapholunären Bandes sind die häufigste Ursache für eine karpale Instabilität. Sie können isoliert oder im Rahmen multilokulärer Verletzungen auftreten. Während Stressaufnahmen und Fluoroskopie die Unterscheidung zwischen dynamischen und statischen Formen der karpalen Instabilität erleichtern, gelingt die direkte Darstellung einer intrinsischen Bandläsion nur mittels MRT und CT- bzw. MR-Arthrografie.

\section{Kernaussagen:}

- Karpale Instabilität kann sich unter Belastung (dynamisch) oder in Ruhe (statisch) manifestieren.

- Dissoziative Formen müssen von nicht dissoziativen, adaptiven oder komplexen Entitäten unterschieden werden.

- Am häufigsten werden karpale Instabilitäten durch ein Trauma oder die CPPD-Arthropathie verursacht.

- Fluoroskopie, Stressbildgebung, MR- und CT-Arthrografie können die Diagnosefindung erleichtern.

\section{ABSTRACT}

Background The term "carpal instability" describes different debilitating wrist conditions, in which the carpus is unable to maintain its physiological range of motion and load transfer. Depending on the cause and location of the dysfunction, four groups can be defined: dissociative, non-dissociative, complex, and adaptive carpal instability. As the most common form by far, dissociative carpal instability can further be categorized as dorsal or palmar intercalated segment instability, contingent on the afflicted interosseous ligament.

Method This review article outlines the different entities of carpal instability, their pathophysiology, and their clinical presentation. It further discusses the diagnostic significance of different imaging methods as well as the established treatment options for each form of instability in context with the current literature.

Results and Conclusion Early detection and treatment of carpal instability are essential for preventing carpal osteoarthritis. Traumatic lesions of the scapholunate interosseous ligament are the most frequent cause of instability. They can occur in an isolated fashion or in context with other carpal injuries. While stress imaging and fluoroscopy facilitate the differentiation between dynamic and static forms of carpal instability, only MRI and CT/MR arthrography can directly reveal the extent of ligament discontinuity. 
Key Points:

- Carpal instability can manifest only in motion (dynamic) or at rest (static).

- Dissociative forms must be distinguished from non-dissociative, adaptive, or complex entities.

- Most instabilities are related to traumatic injuries or CPPD arthropathy.
- Fluoroscopy, stress imaging, and MR and CT arthrography are helpful for diagnosis.

\section{Citation Format}

- Grunz JP, Gietzen CH, Grunz K et al. Imaging of Carpal Instabilities. Fortschr Röntgenstr 2021; 193: 139-150

\section{What is "carpal instability"?}

Joints are considered stable if they can maintain their articular relationship for a physiological range of motion and load transfer. To achieve this, any external force affecting the wrist from any direction is counteracted by internal stabilizers that re-establish the status quo. If a joint loses the ability to react adequately to external force vectors, it becomes unstable, resulting in the loss of anatomical congruency in motion or at rest [1, 2]. From a pathophysiological perspective, carpal instabilities can be the result of intrinsic and/or extrinsic factors. "Intrinsic" refers to insufficiency of the primary and secondary wrist stabilizers such as carpal ligaments, joint capsules, flexor, and extensor tendons. Scapholunate or lunotriquetral ligament tears are common examples for this group [3, 4]. "Extrinsic" mostly refers to an abnormal joint surface geometry of the distal forearm section. Incorrectly healed distal radius fractures with pathological joint surface inclination are representatives of this group $[5,6]$.

Clinically, carpal instability causes pain and varying degrees of dysfunction, secondarily leading to progressive osteoarthritis. Complementing trauma and inflammatory anamnesis, the physical examination should include inspection (swelling, deformity, skin injury), checking the active and passive mobility of the wrist, test of grip strength and examination of the neurovascular status [7].

\section{Imaging techniques}

\section{Radiography}

X-ray scans are usually the first kind of imaging a patient receives when reporting with wrist pain or reduced hand mobility. They serve as primary means of fracture detection after trauma and provide valuable information on the stability of the carpus. Several image findings hint at the presence of structural carpal disorder. In dorsopalmar projection, interruption of the carpal arches is suspicious for instability and should be succeeded by further investigation [7]. Instability of the central carpal column is indicated by a triangular (in dorsal extension) or crescent shape (in palmar flexion) of the lunate $[7,8]$. In the lateral view, any angulation that exceeds the standard values of $>$ Table 1 must be considered pathological, pointing to intercalated segment instability. $>$ Fig. 1 depicts the most frequent carpal instability forms with corresponding pathological angle measurements. It is important to know that severe ligament injuries can be present without evident signs of instability in radiography at rest. To detect these dynamic instabilities, additional stress imaging is recommended $[9,10]$.

\section{Cinematography}

Fluoroscopy may be helpful if suspected instability cannot be explained by rest and stress images. Recordings of wrist motion can be customized depending on the causative pathology. In suspected scapholunate dissociation, dorsopalmar recordings of radio-ulnar deviation usually suffice to secure the diagnosis. In contrast, lateral projections are preferable to visualize midcarpal instability, as the characteristic "clicking" or "snapping" can be provoked in radio-ulnar deviation or flexion and extension of the wrist. An additional series of movements in which patients provoke the click or snap effect themselves might also be helpful $[11,12]$.

\section{MRI}

Due to the complex structure of the wrist, MRI requirements include high spatial resolution as well as optimized signal-to-noise (SNR) and contrast-to-noise ratio (CNR). Technically, multi-channel phased-array coils and 3.0 Tesla scanners are considered the state of the art. While promising results can be achieved with stronger magnets up to 7.0 Tesla, these ultra-high field systems are not established in the clinical routine thus far. Volume coverage is preferably performed with interleaved acquisition. The slice thickness for $2 \mathrm{D}$ and partitions for $3 \mathrm{D}$ imaging should not exceed $2 \mathrm{~mm}$ and $0.5 \mathrm{~mm}$, respectively. Narrowing the field of view to $60-80 \mathrm{~mm}$ provides superior resolution, which is particularly important for the depiction of microstructural alterations [5].

- Fig. 2 displays different MRI techniques for the detection of interosseous carpal ligament injury. Without application of contrast agent, ligament injuries can only be visualized in T2-weighted sequences if joint effusion surrounds the rupture site ( $\vee$ Fig. 2a, b). The detection rate of scapholunate and lunotriquetral ligament tears is $55 \%$ to $60 \%$ for plain MRI compared to arthroscopy as the reference standard. In contrast-enhanced MRI, focal gadolinium enhancement in fat-saturated T1-weighted sequences occurs at the rupture site because of hyperemia of the synovial and fibrovascular repair tissue ( $\bullet$ Fig. $2 c, d$ ). The contrast agent accumulation can be observed for about six months after trauma. By intravenous gadolinium administration, the detection rate of intrinsic carpal ligament injuries can be increased to 80$95 \%$.

Direct MR arthrography is a minimally invasive procedure with articular injection of diluted gadolinium under fluoroscopy. Arthrography has major advantages for the examiner who is able to observe the distribution of the contrast medium in different compartments in real time if ligament ruptures are present. Appli- 
- Table 1 Reference values for carpal angulations in lateral radiographs.

- Tab. 1 Referenzwerte für karpale Winkelbestimmungen im seitlichen Röntgenbild.

\begin{tabular}{|l|l|}
\hline angle & reference (range) \\
\hline radiolunate angle & $0^{\circ}\left(-15^{\circ}\right.$ to $\left.15^{\circ}\right)$ \\
\hline radioscaphoid angle & $45^{\circ}\left(30^{\circ}\right.$ to $\left.60^{\circ}\right)$ \\
\hline capitolunate angle & $0^{\circ}\left(-15^{\circ}\right.$ to $\left.15^{\circ}\right)$ \\
\hline scapholunate angle & $45^{\circ}\left(30^{\circ}\right.$ to $\left.60^{\circ}\right)$ \\
\hline
\end{tabular}

cation of contrast agent further leads to distension of carpal joints, improving discernibility of the intrinsic ligaments from the surrounding articular cartilage. Moreover, the injected gadolinium increases the contrast around the ligaments by T1 shortening ( $\triangleright$ Fig. 2e). Compared to arthroscopy, direct MR arthrography has a sensitivity and specificity of more than $90 \%$ each [13-17]. Despite being relatively easy to conduct, MR arthrography of the wrist remains a specialized procedure that is not performed at many centers.

\section{CT}

The benefit of CT scans in early stages of carpal instability is mostly insignificant. In late stages, however, CT is the method of choice to depict arthrosis in the radioscaphoid and midcarpal joints due to superior visualization of articular surface incongruities, cartilage defects, and subchondral sclerosis $[15,17]$. While ligamentous causes of instability are not directly visible in plain computed tomography, CT imaging after multi-compartment arthrography of the wrist has high diagnostic value for interosseous ligament lesions, achieving comparable results to MR arthrography in the detection of scapholunate and lunotriquetral ligament injuries ( $\triangleright$ Fig. 2f) $[16,18,19]$. Furthermore, high-resolution CT in thin slice technique is considered the diagnostic reference standard in primary imaging of scaphoid fractures. With scaphoid displacement being a common reason for dissociative instability, early CT examinations can prevent delayed diagnosis and immobilization with increased risk for nonunion.

\section{Novel imaging techniques}

Cone-beam computed tomography (CBCT) portrays an alternative approach to $C T$ imaging that was first established for dental and maxillofacial applications in the $1980 \mathrm{~s}$. Combining pyramidshaped beam geometry with large-scale flat-panel detectors, CBCT can provide superior spatial resolution compared to conventional multidetector CT at a low radiation dose [20]. Due to the emergence of dedicated extremity scanners in the last decade, CBCT has gained increasing attention for appendicular skeletal imaging. With the current generation of multi-use systems that are also capable of radiography and fluoroscopy, CBCT possesses potential for "one-stop-shop" imaging, possibly superseding mul- a

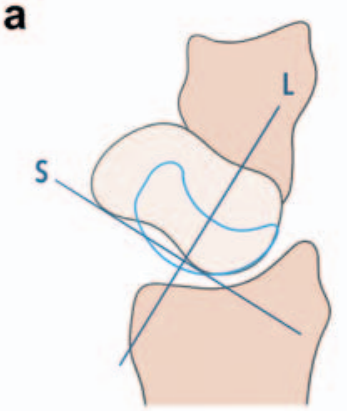

b

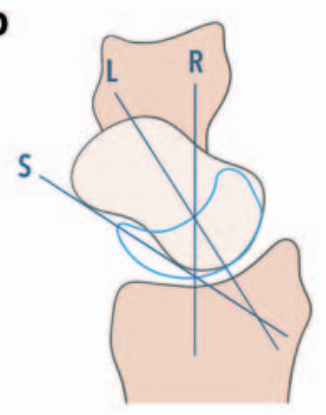

C

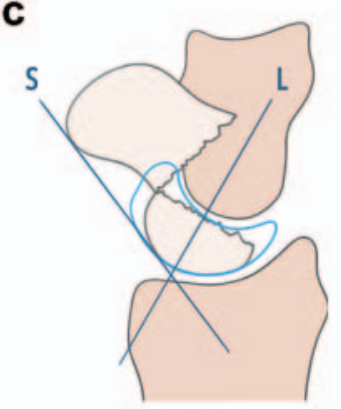

d

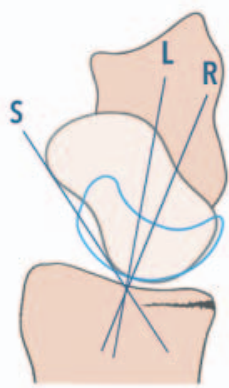

- Fig. 1 For angle measurements in lateral radiographs, the longitudinal axes of the radius $(\mathrm{R})$ and lunate $(\mathrm{L})$ as well as the palmar tangent of the scaphoid (S) are required. a Scapholunate dissociation. Palmar flexion of the scaphoid and dorsal extension of the lunate result in pathologic widening of the scapholunate angle (above $60-70^{\circ}$ ). b Lunotriquetral dissociation. Simultaneous flexion of the scaphoid and lunate results in widening of the radiolunate (above $15^{\circ}$ ) and radioscaphoid (above $60^{\circ}$ ) angles, while the scapholunate angle remains within the normal range or decreases (below $30^{\circ}$ ). c Unstable scaphoid nonunion. The proximal scaphoid fragment and lunate bone extend dorsally, while the distal scaphoid fragment rotates to palmar. The scapholunate angle is subsequently increased (above 60-70 ). d Radiocarpal structural disorder. Pathological inclination of the radial articular surface after fracture leads to combined dorsal extension of the scaphoid and lunate. Therefore, the radiolunate angle decreases (below $-15^{\circ}$ ), while the radioscaphoid angle remains normal or decreases (below $30^{\circ}$ ).

- Abb. 1 Für Winkelmessungen im seitlichen Projektionsradiogramm werden die Längsachsen von Radius (R) und Lunatum (L) sowie die palmare Tangente am Skaphoid (S) benötigt. a Skapholunäre Dissoziation. Palmare Flexion von Skaphoid und dorsale Extension von Lunatum führen zu einer pathologischen Erweiterung des skapholunären Winkels (über $60-70^{\circ}$ ). b Lunotriquetrale Dissoziation. Gleichzeitige Flexion von Skaphoid und Lunatum resultiert in einer Zunahme des radiolunären (über $15^{\circ}$ ) und radioskaphoidalen (über $60^{\circ}$ ) Winkels, während der skapholunäre Winkel im Referenzbereich bleibt oder abnimmt (unter $30^{\circ}$ ). c Instabile Kahnbeinpseudarthrose. Dorsalextension von proximalem Kahnbeinfragment und Lunatum bei simultaner Palmarflexion des distalen Skaphoidfragments führen zu einer Aufweitung des skapholunären Winkels (über $60-70^{\circ}$ ). d Radiokarpale Gefügestörung. Aufgrund der pathologischen Inklination der distalen Radiuskonsole kommt es zu einer Dorsalextension von Skaphoid und Lunatum. Dadurch verkleinert sich der radiolunäre Winkel (unter $-15^{\circ}$ ), der radioskaphoidale Winkel bleibt normal oder nimmt ebenfalls ab (unter $30^{\circ}$ ). 

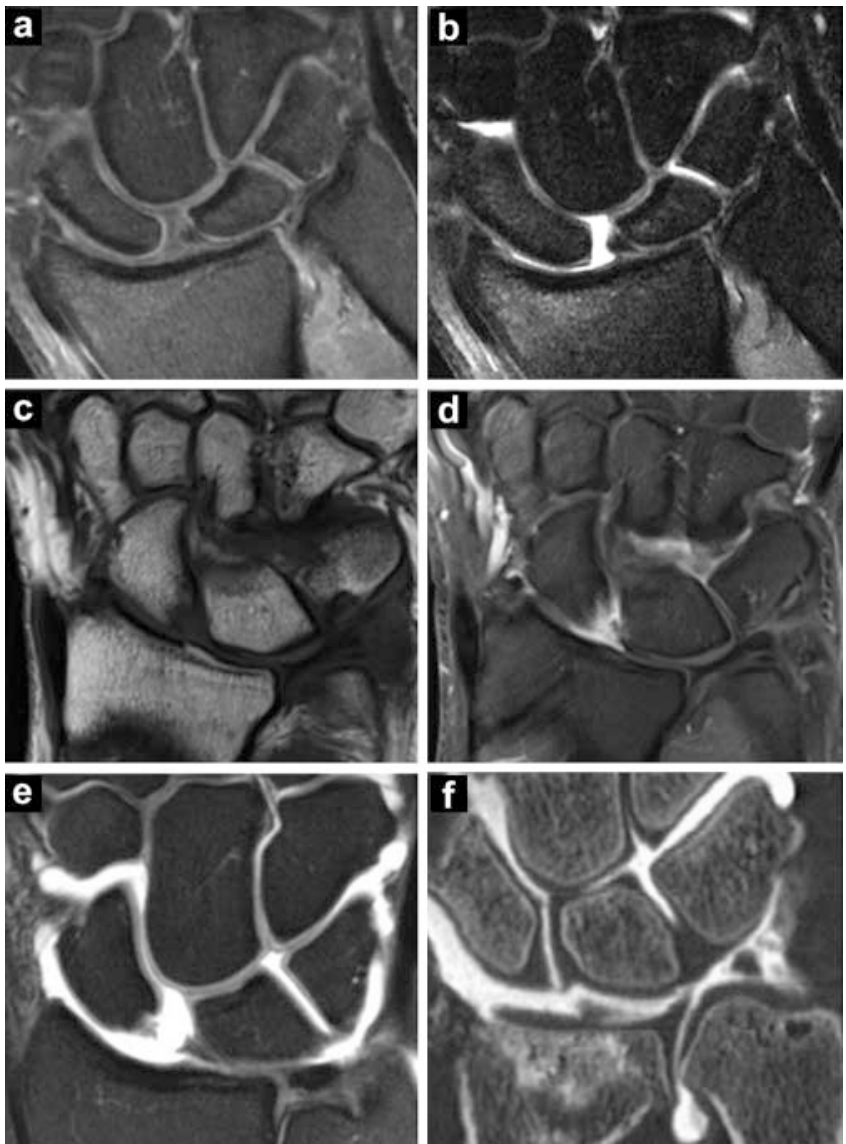

- Fig. 2 Imaging of scapholunate ligament injury using fat-saturated (fs) fast spin echo (FSE) sequences and MR/CT arthrography. a T1 FSE fs b PD-weighted FSE fs c T1 FSE d T1 FSE fs after intravenous application of gadolinium e T1 FSE fs after multicompartment wrist arthrography $\mathbf{f}$ Multidetector $\mathrm{CT}$ after multicompartment wrist arthrography

- Abb. 2 Bildgebende Diagnostik skapholunärer Bandläsionen mittels fettgesättigter (fs) Fast-Spin-Echo (FSE) -Sequenzen sowie MR-/CT-Arthrografie. a T1-FSE fs. b PD-FSE fs. c T1-FSE. d T1-FSE fs nach intravenöser Kontrastmittelapplikation. e T1-FSE fs nach Mehrkompartment-Arthrografie. f Multidetektor-CT nach Mehrkompartment-Arthrografie.

tidetector $\mathrm{CT}$ in the near future for trauma imaging tasks, such as the diagnosis of carpal instability.

Combining the benefits of motion recording with $3 \mathrm{D}$ imaging, dynamic MRI and "four-dimensional CT" (three spatial dimensions + time) present another promising concept for the visualization of wrist kinematics. While fluoroscopic cinematography remains limited to the detection of structural misalignments, these imaging approaches can simultaneously provide additional information about bone microarchitecture, adjacent cartilage and even depict the interosseous carpal ligaments (in case of dynamic MRI). Clinical applicability has been shown for either technique in recent years. However, both dynamic CT and MRI are still considered specialized procedures not regularly performed in the clinical routine $[21,22]$.

\section{Forms of carpal instability}

Four main groups of carpal instability can be discerned: dissociative, non-dissociative, complex and adaptive instabilities [8]. Differentiation between these forms is essential for choosing the right treatment. Imaging of the wrist is particularly challenging as multiple anatomical components collaborate to ensure stability and different microstructural alterations can lead to similar clinical symptoms. Therefore, diagnosis depends on thorough anamnesis and examination, understanding of the biomechanical concepts of mobility and load distribution as well as correct application and interpretation of diagnostic imaging [5, 23].

\section{Dissociative carpal instabilities (CID)}

In dissociative disorders, the components of the proximal carpal row are displaced with respect to each other: If an intrinsic ligament is ruptured, either the scaphoid is shifted in the opposite direction of the lunate or the lunate is shifted in the opposite direction of the triquetrum $[24,25]$. In the presence of a scaphoid fracture/nonunion, the two scaphoid bone fragments can be displaced with respect to each other [26]. CID is by far the most common form of carpal instability with scapholunate dissociation being the most frequent pathoanatomical correlate [13, 27]. The lunate as an intercalated and potentially unstable member of the carpus can present different forms of misalignment. Dorsiflexed intercalated segment instability (DISI) is described when the lunate rotates into extension, widening the radiolunate angle. This constellation is most frequently encountered in scapholunate dissociation. In contrast, palmar-flexed intercalated segment instability (PISI) is present with flexion of the lunate to palmar. This rather rare finding can be seen in midcarpal instability and lunotriquetral dissociation [17, 28]. The acronyms "DISI" and "PISI" are descriptions for the pathological arrangement of the lunate in the central carpal column, but do not describe independent clinical conditions.

\section{Scapholunate dissociation (SLD)}

\section{Pathoanatomy}

Ruptures of the scapholunate ligament (SLL) are mostly traumaassociated, often occurring after a fall on the dorsally extended hand. About $10 \%$ of radius fractures that involve the radiocarpal joint are associated with SLL tears [6, 14]. If SLD is observed without adequate trauma in the patient history, particularly calcium pyrophosphate dihydrate (CPPD) arthropathy has to be evaluated. Discontinuities are mostly located off-center in the scaphoid portion of the ligament [5]. Isolated injury of the SLL results in the scaphoid and lunate rotating in different directions, resulting in a dissociative structural disorder (CID-DISI) [8, 24, 29].

\section{Clinical presentation}

Acute SLD is characterized by radial-sided swelling, dorsal pressure pain, and limited wrist mobility [30]. Watson's scaphoid displacement test is important for diagnosis. The examiner tries to induce a dorsal subluxation of the proximal scaphoid pole by applying volar pressure to the scaphoid tubercle, while the wrist is 


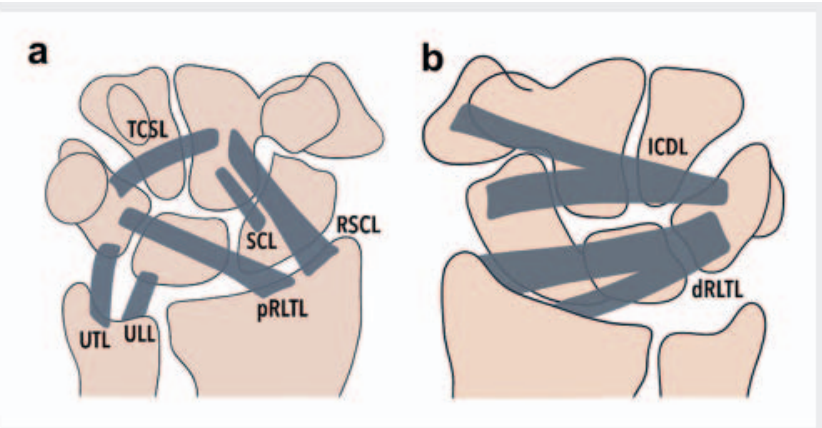

- Fig. 3 Schematic display of intracapsular carpal ligaments. a Palmar "V" ligaments. The proximal palmar " $\mathrm{V}$ " consists of the palmar radiolunotriquetral ligament ( $p R L T L$ ) on the radial side and the ulnolunate (ULL) and ulnotriquetral ligaments (UTL) on the ulnar side. The radial leg of the distal palmar " $\mathrm{V}$ " is formed by the radioscaphocapitate (RSCL) and scaphocapitate ligament $(\mathrm{SCL})$, while the triquetrocapitoscaphoid ligament (TCSL = arcuate ligament) constitutes its ulnar leg. b Dorsal "V" ligaments. In contrast to the palmar side, the ligamentous anatomy of the dorsal carpus resembles a horizontal "V" with the dorsal radiolunotriquetral ligament (dRLTL) as the proximal leg and the intercarpal dorsal ligament (ICDL) as the distal leg.

- Abb. 3 Schematische Darstellung der intrakapsulären karpalen Ligamente. a Palmare V-Bänder. Das proximale palmare „V“ besteht aus dem Lig. radiolunotriquetrum palmare (pRLTL) auf der radialen Seite und den ulnolunären (ULL) und ulnotriquetralen Ligamenten (UTL) auf der ulnaren Seite. Der radiale Schenkel des distalen palmaren „V“ wird durch das Lig. radioscaphocapitatum (RSCL) und das Lig. scaphocapitatum (SCL) gebildet, während das Lig. triquetrocapitoscaphoideum (TCSL = Lig. arcuatum) als ulnarer Schenkel fungiert. b Dorsale V-Bänder. Im Gegensatz zu den palmaren Bändern ähnelt die Bandanatomie der dorsalen Seite einem horizontalen „V“, bei dem das Lig. radiolunotriquetrum dorsale (dRLTL) den proximalen Schenkel und das Lig. intercarpale dorsale (ICDL) den distalen Schenkel darstellt.

simultaneously moved from ulnar to radial deviation with the other hand. If the SLL is disrupted, the scaphoid will subluxate over the dorsal edge of the distal radius and the patient will experience significant pain during the maneuver [31].

\section{Staging}

In stages I and II, radiography under resting conditions is inconspicuous despite a partial or complete rupture of the SLL. Dynamic instability only becomes evident in stress imaging or fluoroscopy and is not visible without load or movement [29, 32]. It manifests if the extrinsic carpal ligaments, i. e., the scaphotrapeziotrapezoid (STTL), radioscaphocapitate (RSCL), palmar (pRLTL), and dorsal radiolunotriquetral ligaments ( $d R L T L$ ), that function as the secondary stabilizers of the wrist remain intact ( $\triangleright$ Fig. 3) [33]. In contrast, combined injury of the SLL and secondary stabilizers results in static instability that can be diagnosed at rest $[8,25]$. Stage III is characterized by simultaneous rotary subluxation of the scaphoid (RSS), as well as DISI configuration of the central carpal column ( $\bullet$ Fig. 4). In the lateral radiograph, widening of the scapholunate angle is present. Dorsopalmar images might show additional widening of the scapholunate gap to more than $3 \mathrm{~mm}$ ("Terry Thomas sign"). How-
- Table 2 Watson and Black's classification of scapholunate dissociation, modified by Schmitt [2, 37].

- Tab. 2 Klassifikation skapholunärer Dissoziationen nach Watson und Black, modifiziert durch Schmitt [2, 37].

\begin{tabular}{|l|l|l|l|}
\hline stage & severity & $\begin{array}{l}\text { scapholunate } \\
\text { ligament }\end{array}$ & $\begin{array}{l}\text { secondary } \\
\text { stabilizers }\end{array}$ \\
\hline $\mathbf{I}$ & pre-dynamic & partial tear & intact \\
\hline II & dynamic & complete tear & intact \\
\hline III & static & complete tear & ruptured \\
\hline IV & arthritis & complete tear & ruptured \\
\hline
\end{tabular}

ever, this is not mandatory ( $\triangleright$ Fig. 5) [34]. Finally, osteoarthritis and loss of carpal height indicate stage IV of SLD, the so-called SLAC wrist (Scapholunate Dissociation Advanced Collapse). Depending on the extent of arthrosis, SLAC I (only radioscaphoid joint), II (entire radiocarpal joint) and III (additional midcarpal joint osteoarthritis) can be differentiated [18, 35-37]. Ligament conditions in different stages of SLD are summarized in > Table 2.

\section{Therapy}

Depending on the severity and acuteness of the instability, treatment options include immobilization, scapholunate transfixation, ligament suture, plasty of the extrinsic ligaments (dorsal capsulodesis), stabilization of the scaphoid with a tendon strip or partial arthrodesis, implantation of bone-ligament-bone grafts, as well as salvage procedures in late stages with advanced osteoarthritis [27, 35, 38, 39].

\section{Lunotriquetral dissociation (LTD)}

\section{Pathoanatomy}

Compared to SLD, LTD is a rare condition $[4,13,14]$. Injuries of the lunotriquetral ligament (LTL) occur through axial trauma to the pronated wrist, often associated with perilunate dislocation injuries. For LTL injuries to become clinically apparent, additional insufficiency of the secondary stabilizers is necessary, mostly of the pRLTL and dRLTL $[5,40]$. In LTD, the triquetrum extends dorsally, while the lunate rotates in the palmar direction. Due to maintained connection through the SLL, the scaphoid follows the lunate's rotation to a lesser extent, thus reducing the scapholunate angle to less than $30^{\circ}$ ( $\triangleright$ Fig. 6) $[4,8]$. The resulting PISI deformity of the central carpal column displays pathological widening of the radiolunate and capitolunate angles. Similar to SLD, carpal height is reduced in advanced LTD [25, 41]. The dissociative structural disorder (CID-PISI) caused by instability of the lunotriquetral compartment must be distinguished from midcarpal instability, a non-dissociative disorder that is also characterized by palmar flexion of the lunate (CIND-PISI). LTL injuries are frequently associated with lesions of the triangular fibrocartilage complex (TFCC) $[13,42]$. 


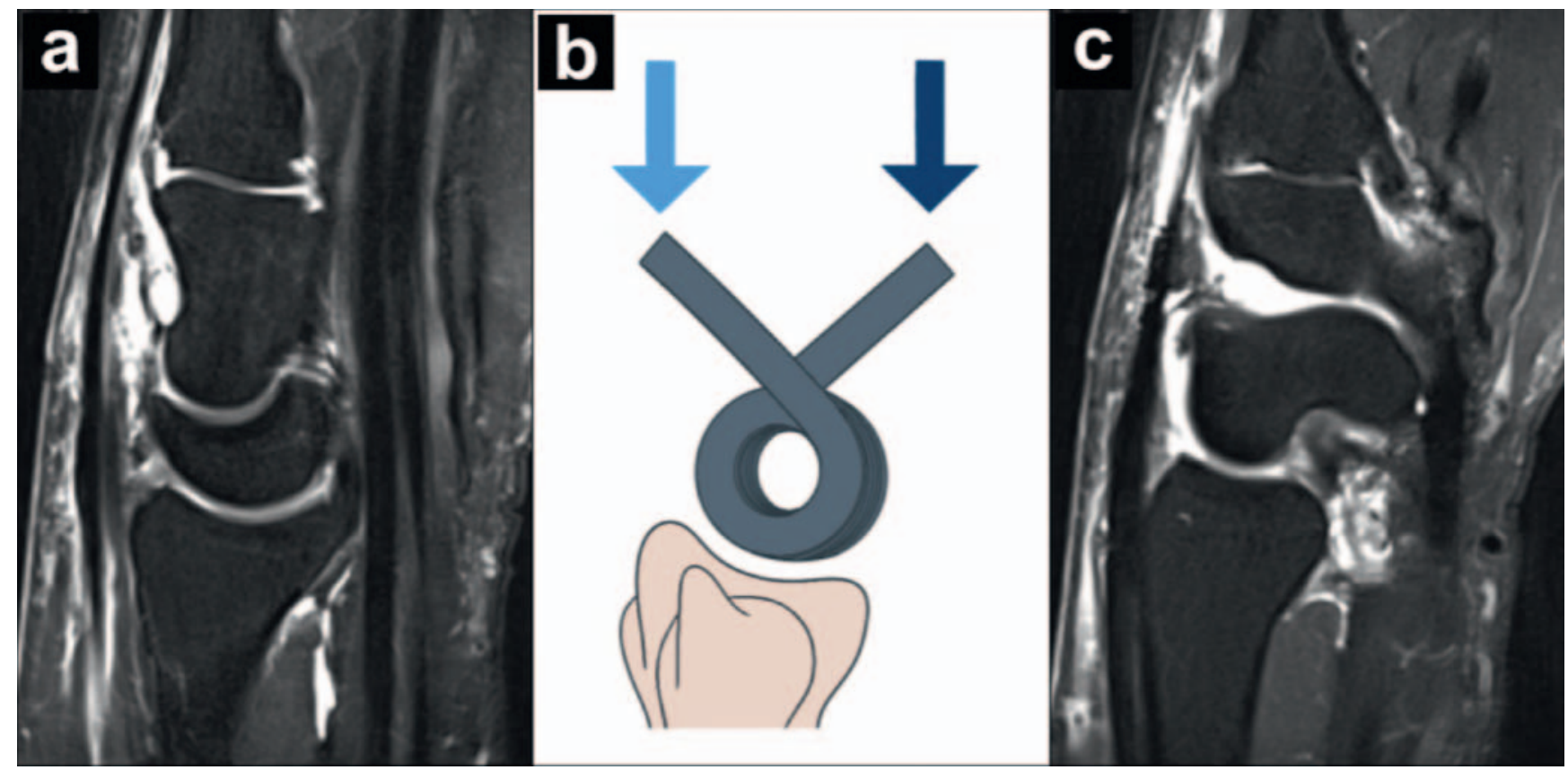

- Fig. 4 Rotational deformities in scapholunate dissociation a Dorsal extension of the lunate (DISI configuration) in sagittal T1 FSE fs after wrist arthrography $\mathbf{b}$ Schematic display of opposite rotational tendencies of the scaphoid and lunate in scapholunate dissociation $\mathbf{c}$ Palmar flexion of the scaphoid in sagittal T1 FSE after wrist arthrography

- Abb.4 Rotationsfehlstellungen bei skapholunärer Dissoziation. a Dorsalextension des Os lunatum (DISI-Konfiguration) in sagittaler T1-FSE fs nach karpaler Arthrografie. b Schematische Darstellung der entgegengesetzten Rotationstendenzen von Skaphoid und Lunatum bei skapholunärer Dissoziation. c Palmarflexion des Os scaphoideum in sagittaler T1-FSE fs nach karpaler Arthrografie.
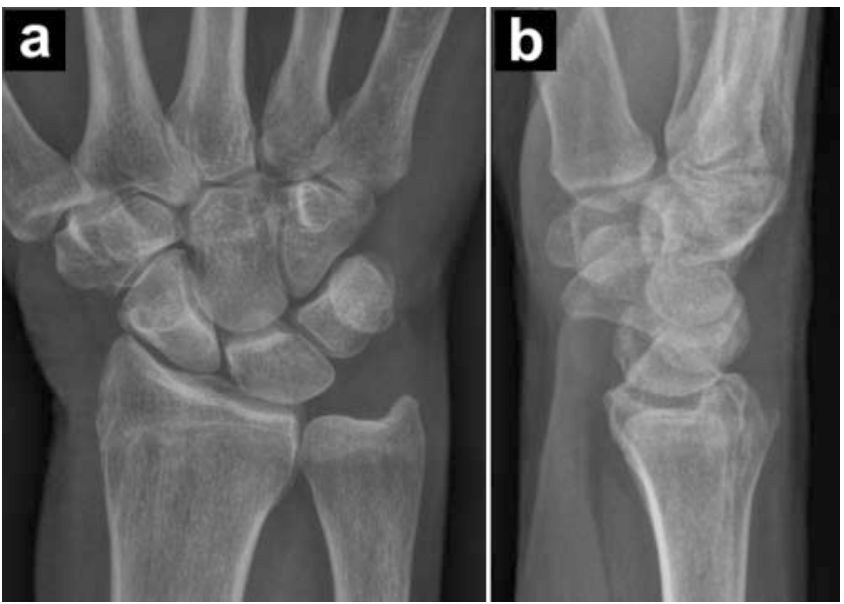

- Fig. 5 Static form of scapholunate dissociation a Despite static instability, scapholunate distance can appear normal in dorsopalmar projection. b Lateral view, however, shows the characteristic combination of dorsally extended lunate and rotatory subluxation of the scaphoid, resulting in pathologic widening of the scapholunate angle (above $70^{\circ}$ ).

- Abb. 5 Statische Form der skapholunären Dissoziation. a Im dorsopalmaren Röntgenbild kann die Distanz zwischen Skaphoid und Lunatum auch bei statischen Dissoziationen normwertig erscheinen. b Die seitliche Aufnahme zeigt jedoch die typische Kombination aus Dorsalextension des Mondbeins und Rotationssubluxation des Kahnbeins mit folglich pathologischer Erweiterung des skapholunären Winkels (über $70^{\circ}$ ).

\section{Clinical presentation}

Patients report ulnar-sided wrist pain and click effects during dorsal extension and ulnar deviation. Pressure pain can be induced over the lunotriquetral joint and Reagan's ballottement test is positive (painful displacement of the triquetrum in relation to the lunate under pressure) [2].

\section{Staging}

A classification similar to the one used in SLD is recommended. In stages I and II of LTD, due to the stabilizing effect of the PRLTL, dRLTL and ulnocarpal ligaments, structural arrangement of the carpus remains normal at rest. When the secondary stabilizers are also injured, static disorders become evident in stages III and IV. Slightly differing from the SLD classification, asymptomatic stage I of LTD can include a complete tear of the LTL. In stage II, characterized by pain in motion and dynamic instability detectable in fluoroscopy or stress imaging, additional discontinuity of the pRLTL is present. Stage III relates to static structural disorders without accompanying degeneration. In stage IV of LTD, carpal osteoarthritis has manifested $[5,13,41]$.

\section{Therapy}

Treatment of LTD remains controversial. In acute injury, repositioning and lunotriquetral transfixation is performed. In the case of TFCC and LTL lesions associated with increased ulna length and subsequent carpal osteoarthritis, ulna shortening through os- 


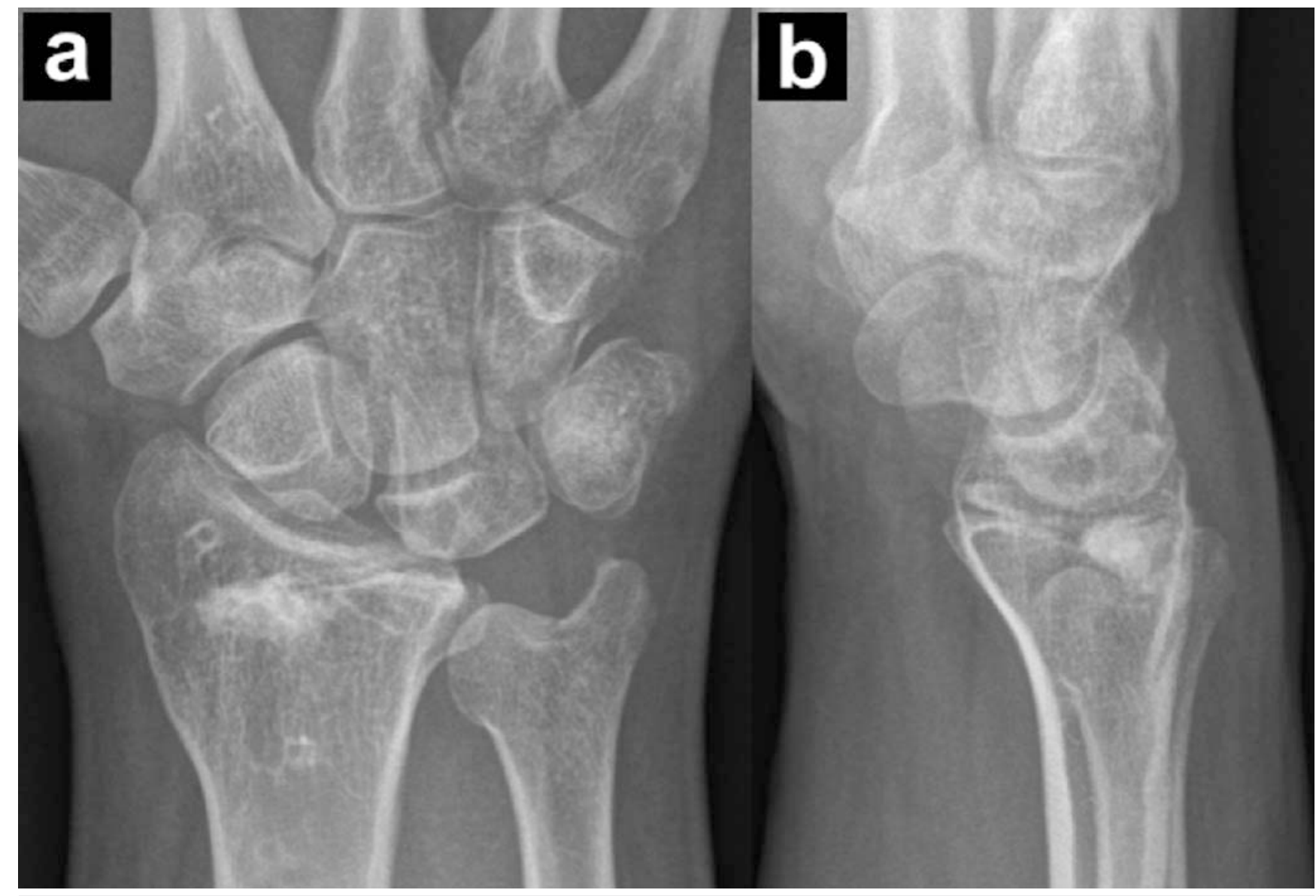

- Fig. 6 Static form of lunotriquetral dissociation a After healing of a distal radius fracture and removal of the osteosynthesis plate, incongruence of the lunotriquetral articulation and interruption of the proximal carpal arch is present in the dorsopalmar view. $\mathbf{b}$ The lunate has adopted a palmar rotary subluxation in the lateral view (PISI). The scapholunate angle has decreased below $30^{\circ}$.

- Abb. 6 Statische Form der lunotriquetralen Dissoziation. a Nach Heilung einer distalen Radiusfraktur und Entfernung der Osteosyntheseplatte liegt in der dorsopalmaren Aufnahme eine Inkongruenz der lunotriquetralen Artikulation mit Unterbrechung des proximalen Karpalbogens vor. b Das seitliche Röntgenbild zeigt, dass sich das Lunatum in einer palmar gerichteten Rotationssubluxation befindet (PISI). Der skapholunäre Winkel beträgt weniger als $30^{\circ}$.

teotomy is recommended. In the case of static PISI disorders and a normal ulna length, lunotriquetral arthrodesis or ligament replacement surgery may be appropriate [41, 43].

\section{Scaphoid nonunion}

\section{Pathoanatomy}

In displaced scaphoid nonunion, an osseous form of dissociative instability is present. While the proximal scaphoid fragment is detached from the carpal alignment and subsequently follows its natural tendency into an extension position, the distal fragment moves into a flexion position due to the axial load. Interconnected to the proximal scaphoid fragment by the SLL and LTL, the lunate and triquetrum also rotate into extension, resulting in a DISI configuration of the central carpal column [26]. > Fig. 7 depicts the combination of scaphoid nonunion, osteoarthritis and carpal collapse named SNAC wrist (Scaphoid Nonunion Advanced Collapse) [18, 35].

\section{Clinical presentation}

The healing of a scaphoid fracture should be completed after about three months. If fracture consolidation has not taken place at this time, healing is delayed. After six months, nonunion can be described [5]. The symptoms of scaphoid nonunion are manifold. Early stages can cause moderate pain during radial wrist deviation or thumb flexion. In the case of carpal instability, stress-related symptoms increase and swelling of the radial wrist occurs. In the stage of osteoarthritis, the wrist can also be limited in strength $[18,35]$.

\section{Staging}

In delayed union, decreasing mineralization around the fracture gap becomes evident. If no bony consolidation occurs, pseudocystic resorption areas in both scaphoid fragments indicate the irreversible onset of nonunion $[5,36]$. The ensuing sclerosis of the fragment edges can either be smooth (atrophic form) or bulgy through formation of osteophytes (hypertrophic form). Depend- 


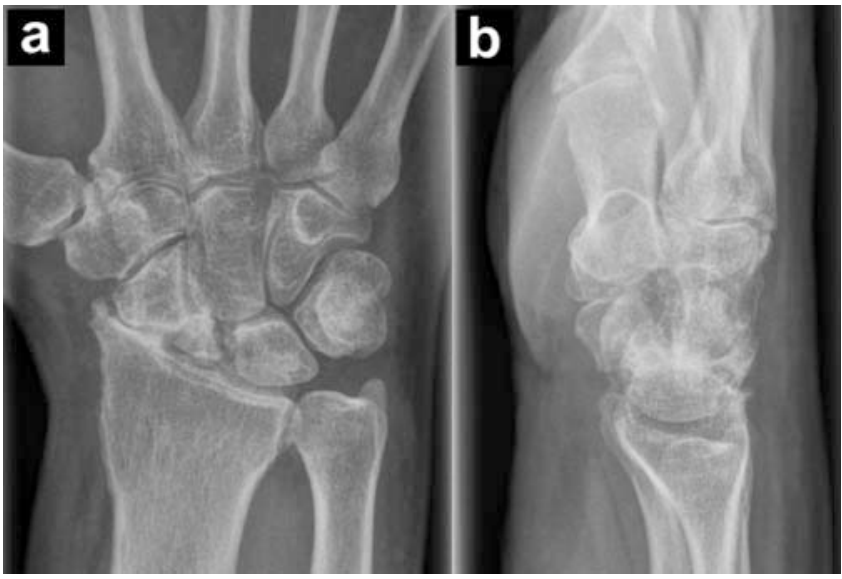

- Fig. 7 Scaphoid nonunion advanced collapse (SNAC wrist) a Dorsopalmar view depicts nonunion of the scaphoid and advanced osteoarthritis in the radiocarpal and (less pronounced) midcarpal joints. Carpal height is reduced. b Lateral view shows dorsal extension of the lunate alongside the proximal scaphoid fragment with resulting DISI configuration. The distal scaphoid fragment adopts a compensatory flexion position.

- Abb. 7 Karpaler Kollaps bei Skaphoidpseudarthrose (SNAC wrist). a Die dorsopalmare Röntgenaufnahme zeigt eine Pseudarthrose des Kahnbeins mit fortgeschrittenen arthrotischen Veränderungen im radiokarpalen und (weniger ausgeprägt) im mediokarpalen Gelenk. Die Höhe des Karpus ist reduziert. b In der seitlichen Ansicht kommt die Dorsalextension von Lunatum und proximalem Skaphoidfragment mit resultierender DISI-Fehlstellung zur Darstellung. Das distale Kahnbeinfragment nimmt eine kompensatorische Flexionsposition ein.

ing on the filling tissue in the gap, unstable and stable nonunion can be distinguished. Unstable nonunion leads to secondary osteoarthritis, beginning between the radial styloid and distal scaphoid fragment (SNAC I). In later stages, the midcarpal joint is also affected, starting between the proximal scaphoid fragment and the capitate head (SNAC II) and before reaching the articular surfaces between the capitate head and the lunate (SNAC III) [35].

\section{Therapy}

Depending on the stage of scaphoid nonunion, different surgical approaches can be used. In the case of mere nonunion, spongiosaplasty and transfixation are commonly performed. If the proximal scaphoid fragment is also necrotic, corticocancellous bone grafts from the radius, iliac crest, or femoral condyle can be inserted into the defect and connected with the palmar or dorsal blood vessels of the wrist to revascularize the surrounding tissue [35, 44].

\section{Non-dissociative carpal instabilities (CIND)}

In CIND, the proximal carpal row is intact. However, it is either incorrectly aligned with the distal carpal row or dislocated from the forearm. Pathoanatomically, lesions of the extrinsic intracapsular ligaments or a displaced radius joint surface is causative for development of CIND [45, 46].

\section{Radiocarpal instability ( $\mathrm{RCl})$}

\section{Ulnar translocation}

The slingshot ligaments, namely the radioscaphocapitate ligament (RSCL), pRLTL, and dRLTL, antagonize the natural tendency of the carpalia for ulnar deviation that is based on the inclination of the distal radius joint surface. If the slingshot ligaments become insufficient, the entire carpus drifts to the ulnar side, subsequently effecting the physiological load distribution from the wrist to the distal forearm [9, 23]. Apart from traumatic injuries, later stages of rheumatoid arthritis or CPPD arthropathy can also cause ulnar (and palmar) deviation of the wrist through inflammatory ligament destruction. Translocation may further be induced by extensive surgical resection of the radial styloid or the ulnar head. In Madelung deformity, a congenital disorder characterized by exaggerated palmar and ulnar tilt of the radiocarpal articulation, excessive ligament loading leads to insufficiency and carpal translocation over time. Two forms of ulnar translocation can be differentiated according to Taleisnik [47]: In the first form, the entire carpus deviates towards the ulnar side, resulting in a gap of more than $2 \mathrm{~mm}$ between the radial styloid and scaphoid, while the lunate loses its contact with the radius. In the second form, the scaphoid stays in place, while the remaining carpus drifts to the ulnar side, consecutively widening the scapholunate gap. Differentiation of the latter condition and isolated SLD is important for treatment $[2,30]$.

\section{Radial translocation}

Decreased inclination of the radial articular surface may cause radial (or dorsal) dislocation of the proximal carpal row ( $\triangleright$ Fig. 8). Radial translocation of the carpus mainly occurs in displaced Chauffeur's fractures (fractures of the radial styloid process) [26]. Loss of bone substance due to friction between the distal radius and scaphoid in SLAC or SNAC wrist can also lead to radial shifting of the wrist [37]. In all forms of carpal translocation, incongruence of the radiocarpal joint surfaces results in earlyonset osteoarthritis [36].

\section{Midcarpal instability (MCI)}

\section{Instability of the entire midcarpal joint}

The characteristic feature of $\mathrm{MCl}$ is the abnormal mobility of the proximal carpal row in motion or at rest. In radial deviation of the wrist, the proximal carpal row adopts a flexion position (CIND-PISI), while ulnar deviation of the wrist triggers the proximal carpalia to extend dorsally (CIND-DISI). With both tiers behaving like separate entities instead of one unit, the distal row of the carpus rotates in the opposite direction of the proximal row [24].

Insufficiency of the dRLTL on the dorsal side and the triquetrocapitoscaphoid ligament (TCSL = arcuate ligament) on the palmar side are suspected to induce midcarpal joint disorders. During radial deviation of the wrist, insufficient ligament stability causes the triquetrum to jump from its natural palmar (proximal) to a dorsal (distal) position. Because the SLL and LTL are intact, the sca- 
a

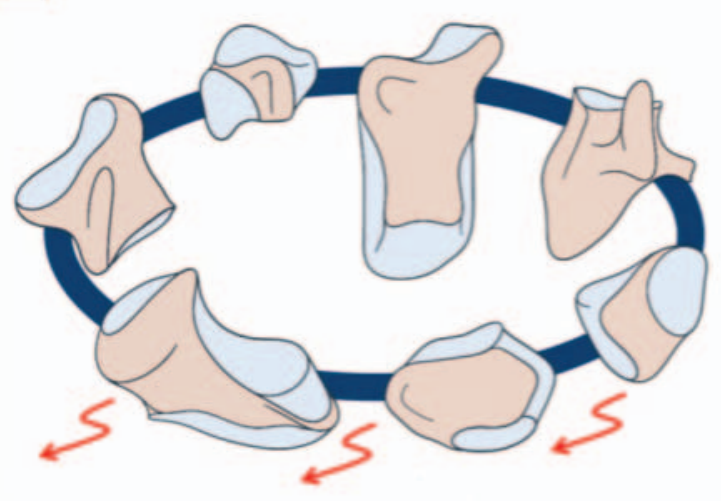

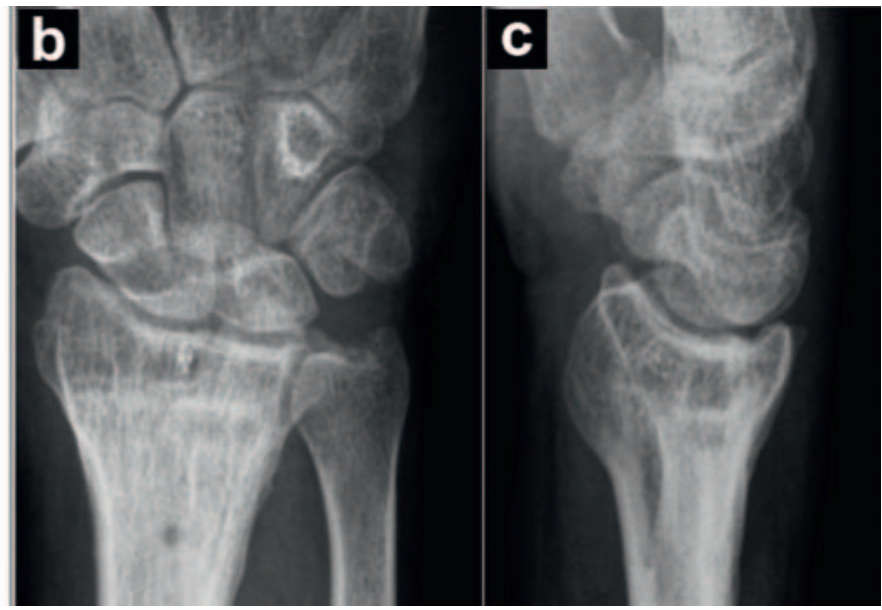

- Fig. 8 Radiocarpal instability a Schematic display of the carpalia as an interconnected ring. Red arrows indicate that the cause of instability is located proximal to the carpus. $\mathbf{b}$ The dorsopalmar view shows a healed distal radius fracture. $\mathbf{c}$ The lateral X-ray reveals the pathological inclination of the radial joint surface and zigzag alignment of the carpus.

- Abb. 8 Radiokarpale Instabilität. a Schematische Darstellung der Carpalia als zusammenhängender Ring. Rote Pfeile zeigen an, dass die Ursache der Instabilität proximal des Karpus liegt. b Die dorsopalmare Ansicht zeigt eine verheilte distale Radiusfraktur. c In der seitlichen Röntgenaufnahme werden die pathologische Neigung der Radiusgelenkfläche und die Zick-Zack-Deformität des Karpus deutlich.

a

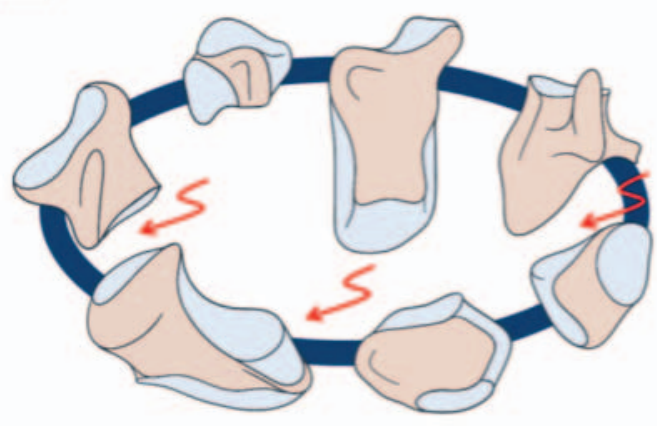

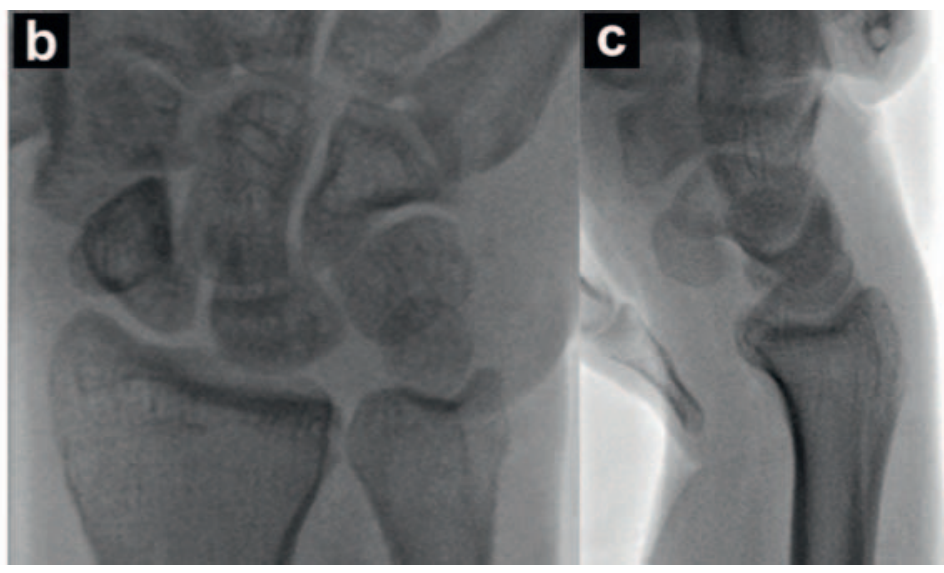

- Fig. 9 Midcarpal instability a Schematic display of the carpalia as an interconnected ring. Red arrows indicate that the cause of instability is located between both carpal rows. b After midcarpal "clicking" during ulnar deviation of the wrist, fluoroscopy shows palmar flexion of the scaphoid and incongruence between the capitate and lunate bones. $\mathbf{c}$ In the lateral projection, flexion of the proximal and extension of the distal carpalia is clearly visible under stress load from the patient's opposite hand. Both the radiolunate and capitolunate angles are pathologically extended (both above $\left.15^{\circ}\right)$.

- Abb.9 Mediokarpale Instabilität. a Schematische Darstellung der Carpalia als zusammenhängender Ring. Rote Pfeile zeigen an, dass die Ursache der Instabilität zwischen den beiden karpalen Reihen liegt. b Nach einem durch ulnare Abduktion provozierten mediokarpalen Klick-Effekt zeigt sich in der Kinematografie eine Palmarflexion des Skaphoids sowie eine Inkongruenz zwischen Kapitatum und Lunatum. c In der lateralen Projektion ist unter Belastung durch die gegenseitige Patientenhand die Flexion der proximalen und Extension der distalen Carpalia gut erkennbar. Sowohl der radiolunäre als auch der kapitolunäre Winkel sind pathologisch aufgeweitet (beide über $15^{\circ}$ ).

phoid and lunate follow the rotation of the triquetrum, with the capitate head dislocating in front of the anterior horn of the lunate ( $\triangleright$ Fig. 9) [26, 46]. MRI has limited applicability for diagnosis of midcarpal instability as all interosseous carpal ligaments present intact. Thus, fluoroscopy imaging in motion is key for differentiating between midcarpal instability and lunotriquetral dissociation.
The "jumping" of the carpal rows causes a moderately painful click effect on the ulnar side of the wrist. Patients can usually trigger the effect themselves during closure of the fist in ulnar deviation. If the clicking can be antagonized through pressure on the pisiform bone, $\mathrm{MCl}$ should be suspected. In late stages, patients might experience severe pain and a weakness of grip [48].

Depending on the underlying cause, therapy can consist of radial osteotomy, capitolunate partial arthrodesis or "four corner fu- 
sion" of lunate, triquetrum, capitate and hamate. Ligament reconstructions of the extrinsic carpal ligaments are rarely successful.

\section{Capitolunate instability}

Referring to a structural disorder limited to the articulation between the capitate head and lunate, this special form of $\mathrm{MCl}$ is only visible in motion and cannot be detected at rest. The capitolunate instability pattern (CLIP) is present if subluxation of at least half the width of the capitate head can be documented in stress imaging. In most cases, the capitate head can only be dislocated dorsally from the lunate $[24,45]$.

\section{Unstable necrosis of the lunate (Kienböck's disease)}

In advanced lunate necrosis (stages IIIb and IV), the decreasing height of the lunate bone has destabilizing effects on the entire wrist. Increased axial load and loss of lunate height cause the scaphoid to move into a flexed position. The loss of carpal height can be quantified using the indices of Youm (reference: $0.54 \pm 0.03$ ) [49] and Nattrass (reference: $1.57 \pm 0.05$ ) [50].

\section{Complex carpal instabilities (CIC)}

Complex instability can refer to different combinations of ligament tears, cartilage injuries and/or luxation fractures. The instability patterns are manifold and mostly contain combinations of dissociative and non-dissociative elements. CIC is mostly seen in high impact accidents, resulting in different perilunate dislocation patterns that are characterized by injuries of the greater and/ or lesser arcs of the wrist $[8,24]$.

\section{Adaptive carpal instabilities (CIA)}

Adaptive instabilities are characterized by an extra-carpal cause of instability, i. e. the causative injury is located proximal to the carpal bones. They can lead to gross deformation and functional incapacity of the hand. The most frequent extrinsic causes of instability are incorrectly healed distal radius fractures with or without concomitant ligament injuries [8,47]. Pathological angulation of the radial joint surface leads to structural disorder of the carpus with the wrist adopting a zigzag-shaped compensatory position relative to the radius. Externally, a fork-like or bayonet-like deformation of the wrist may be noticeable. Unphysiological loading causes pain and swelling as well as early-onset of osteoarthritis [5, 36].

\section{Conclusion}

Wrist function is associated with high individual and socioeconomic relevance. Impairing motion range and grip strength of the hand, carpal instability needs adequate treatment. In order to choose the correct approach from a variety of therapeutic options, surgeons require proper imaging beforehand. As the term "carpal instability" refers to a large number of conditions with different stages and patterns, diagnosis and categorization oftentimes pose intricate challenges ( $\vee$ Table 3 ). The early stages of each entity of carpal instability are particularly difficult to differentiate because radiographic signs might be subtle or even
- Table 3 Characteristics of carpal instability according to Schmitt and Lanz [5].

- Tab.3 Charakteristiken karpaler Instabilitäten nach Schmitt und Lanz [5].

\begin{tabular}{|c|c|c|}
\hline category & subcategory & characteristic \\
\hline \multirow[t]{3}{*}{ time } & acute & 1st week \\
\hline & subacute & 2nd to 6th week \\
\hline & chronic & after 6th week \\
\hline \multirow[t]{3}{*}{ severity } & pre-dynamic & no instability despite predisposition \\
\hline & dynamic & instability in motion \\
\hline & static & instability at rest \\
\hline \multirow[t]{3}{*}{ etiology } & traumatic & e. g. Fall on the outstretched hand \\
\hline & inflammatory & $\begin{array}{l}\text { e. g. CPPD arthropathy, rheumatoid } \\
\text { arthritis }\end{array}$ \\
\hline & congenital & e. g. Madelung deformity \\
\hline \multirow[t]{3}{*}{ direction } & PISI & palmar misalignment of the lunate \\
\hline & DISI & dorsal misalignment of the lunate \\
\hline & translocation & carpal dislocation opposite forearm \\
\hline \multirow[t]{4}{*}{ pattern } & CID & instability in the proximal carpal row \\
\hline & CIND & instability between carpal rows \\
\hline & $\mathrm{CIC}$ & combination of CID and CIND \\
\hline & $\mathrm{CIA}$ & extra-carpal cause of instability \\
\hline
\end{tabular}

CPPD - calcium pyrophosphate dihydrate; PISI - palmar intercalated segment instability; DISI - dorsal intercalated segment instability; CID - carpal instability dissociative; CIND - carpal instability nondissociative; CIC - carpal instability complex; CIA - carpal instability adaptive.

completely missing [2, 9]. With many osseous, ligamentous and cartilaginous structures working together to ensure stability of the wrist, isolated injuries can be compensated by secondary stabilizers and therefore remain inapparent in X-ray scans at rest [40]. The addition of fluoroscopy and stress imaging may help to diagnose these dynamic forms of instability, although the extent of ligament damage cannot be quantified [29, 32]. While radiography is limited to the depiction of structural disorders caused by instability, MR and CT arthrography as well as (dynamic) MRI can directly visualize the actual ligament injury responsible for the instability - in most cases SLL and LTL tears. As osteoarthritis and subsequent disability of the wrist are common results of instability, any radiologist should be aware of this challenging topic and the importance of early and precise diagnosis. Moreover, close collaboration of radiologists and wrist surgeons is necessary to ensure optimal and timely treatment of patients.

\section{Funding}

Interdisciplinary Center of Clinical Research Würzburg, Germany: Z-2/CSP-06 (recipient: Jan-Peter Grunz) 


\section{Conflict of Interest}

The authors received reseach support from a cooperation of the Institute of Diagnostic and Interventional Radiology with Siemens Healthineers.

\section{References}

[1] Cooney W. The Modern History of the Wrist. J. Wrist Surg 2012; 01: 95102

[2] Schmitt R, Froehner S, Coblenz G et al. Carpal instability. Eur. Radiol 2006; 16: 2161-2178

[3] Lee RKL, Griffith JF, Ng AWH et al. Intrinsic carpal ligaments on MR and multidetector $\mathrm{CT}$ arthrography: comparison of axial and axial oblique planes. Eur. Radiol 2017; 27: 1277-1285

[4] Shin AY, Battaglia M], Bishop AT. Lunotriquetral Instability: Diagnosis and Treatment. J. Am. Acad. Orthop. Surg 2000; 8: 170-179

[5] Schmitt R, Lanz U. [Diagnostic Imaging of the Hand]. 3. Edition Stuttgart: Thieme; 2014

[6] Grunz J-P, Gietzen CH, Schmitt R et al. [Distal Radius Fractures: Update on imaging]. Radiologe 2018; 58: 159-174

[7] Gilula L. Carpal injuries: analytic approach and case exercises. Am. J. Roentgenol 1979; 133: 503-517

[8] Kani KK, Mulcahy H, Chew FS. Understanding carpal instability: a radiographic perspective. Skeletal Radiol 2016; 45: 1031-1043

[9] Amadio PC. Carpal kinematics and instability: A clinical and anatomic primer. Clin. Anat 1991; 4: 1-12

[10] Garcia-Elias M. Kinetic analysis of carpal stability during grip. Hand Clin 1997; 13: 151-158

[11] Short WH, Werner FW, Green JK et al. Biomechanical Evaluation of the Ligamentous Stabilizers of the Scaphoid and Lunate: Part III. J. Hand Surg. Am 2007; 32: 297.e1-297.e18

[12] Pliefke J, Stengel D, Rademacher G et al. Diagnostic accuracy of plain radiographs and cineradiography in diagnosing traumatic scapholunate dissociation. Skeletal Radiol 2008; 37: 139-145

[13] Klempka A, Wagner M, Fodor S et al. Injuries of the scapholunate and lunotriquetral ligaments as well as the TFCC in intra-articular distal radius fractures. Prevalence assessed with MDCT arthrography. Eur. Radiol 2016; 26: 722-732

[14] Schmitt R, Christopoulos G, Meier R et al. [Direct MR arthrography of the wrist in comparison with arthroscopy: A prospective study on $125 \mathrm{pa}$ tients]. Rofo 2003; 175: 911-919

[15] Haims AH, Moore AE, Schweitzer ME et al. MRI in the Diagnosis of Cartilage Injury in the Wrist. Am. J. Roentgenol 2004; 182: 1267-1270

[16] Lee RKL, Ng AWH, Tong CSL et al. Intrinsic ligament and triangular fibrocartilage complex tears of the wrist: comparison of MDCT arthrography, conventional 3-T MRI, and MR arthrography. Skeletal Radiol 2013; 42: 1277-1285

[17] Moser T, Dosch J-C, Moussaoui A et al. Wrist Ligament Tears: Evaluation of MRI and Combined MDCT and MR Arthrography. Am. J. Roentgenol 2007; 188: 1278-1286

[18] Crema MD, Zentner J, Guermazi A et al. Scapholunate Advanced Collapse and Scaphoid Nonunion Advanced Collapse: MDCT Arthrography Features. Am. J. Roentgenol 2012; 199: W202-W207

[19] Schmid MR, Schertler T, Pfirrmann CW et al. Interosseous Ligament Tears of the Wrist: Comparison of Multi-Detector Row CT Arthrography and MR Imaging. Radiology 2005; 237: 1008-1013

[20] Grunz J-P, Gietzen CH, Kunz AS et al. Twin Robotic X-Ray System for 3D Cone-Beam CT of the Wrist: An Evaluation of Image Quality and Radiation Dose. Am. J. Roentgenol 2020; 214: 422-427
[21] Shaw CB, Foster BH, Borgese M et al. Real-time three-dimensional MR for the assessment of dynamic carpal instability. PLoS One 2019; 14: e0222704

[22] Rauch A, Arab WA, Dap F et al. Four-dimensional CT Analysis of Wrist Kinematics during Radioulnar Deviation. Radiology 2018; 289: 750-758

[23] Kijima Y, Viegas SF. Wrist Anatomy and Biomechanics. J. Hand Surg. Am 2009; 34: 1555-1563

[24] Ramamurthy NK, Chojnowski AJ, Toms AP. Imaging in carpal instability. J. Hand Surg (European Vol) 2016; 41: 22-34

[25] Mayfield JK, Johnson RP, Kilcoyne RK. Carpal dislocations: Pathomechanics and progressive perilunar instability. J. Hand Surg. Am 1980; 5: 226-241

[26] Linscheid RL, Dobyns JH, Beabout JW et al. Traumatic Instability of the Wrist. J. Bone Jt. Surgery-American Vol 2002; 84: 142

[27] Prommersberger K-J, Mühldorfer-Fodor M, Kalb K et al. Die skapholunäre Bandverletzung. Unfallchirurg 2014; 117: 723-739

[28] Suojärvi N, Haapamäki V, Lindfors $N$ et al. Radiocarpal Injuries: Cone Beam Computed Tomography Arthrography, Magnetic Resonance Arthrography, and Arthroscopic Correlation among 21 Patients. Scand. J. Surg 2017; 106: 173-179

[29] Cheriex KCAL, Sulkers GSI, Terra MP et al. Scapholunate dissociation; diagnostics made easy. Eur. J. Radiol 2017; 92: 45-50

[30] Linn MR, Mann FA, Gilula LA. Imaging the symptomatic wrist. Orthop. Clin. North Am 1990; 21: 515-543

[31] Watson HK, Ashmead D, Makhlouf MV. Examination of the scaphoid. J. Hand Surg. Am 1988; 13: 657-660

[32] Sulkers GSI, Strackee SD, Schep NWL et al. Wrist cineradiography: a protocol for diagnosing carpal instability. J. Hand Surg (European Vol) 2018; 43: 174-178

[33] Padmore C, Stoesser H, Langohr GD et al. Carpal Kinematics following Sequential Scapholunate Ligament Sectioning. J. Wrist Surg 2019; 08: 124-131

[34] Frankel VH. The Terry-Thomas Sign. Clin. Orthop. Relat. Res 1978; 135: 311-312

[35] Krimmer H, Lanz U. [Post-traumatic carpal collapse. Follow-up and therapeutic concept]. Unfallchirurg 2000; 103: 260-266

[36] Laulan J, Marteau E, Bacle G. Wrist osteoarthritis. Orthop. Traumatol. Surg. Res 2015; 101: S1-S9

[37] Watson HK, Ballet FL. The SLAC wrist: Scapholunate advanced collapse pattern of degenerative arthritis. J. Hand Surg. Am 1984; 9: 358-365

[38] Moran SL, Cooney WP, Berger RA et al. Capsulodesis for the treatment of chronic scapholunate instability. J. Hand Surg. Am 2005; 30: 16-23

[39] Wyrick JD. Proximal Row Carpectomy and Intercarpal Arthrodesis for the Management of Wrist Arthritis. J. Am. Acad. Orthop. Surg 2003; 11: 277-281

[40] Theumann NH, Etechami G, Duvoisin B et al. Association between Extrinsic and Intrinsic Carpal Ligament Injuries at MR Arthrography and Carpal Instability at Radiography: Initial Observations. Radiology 2006; 238: 950-957

[41] van de Grift TC, Ritt MJ. Management of lunotriquetral instability: a review of the literature. J. Hand Surg (European Vol) 2016; 41: 72-85

[42] Palmer AK, Werner FW. The triangular fibrocartilage complex of the wrist-Anatomy and function. J. Hand Surg. Am 1981; 6: 153-162

[43] Watanabe A, Souza F, Vezeridis PS et al. Ulnar-sided wrist pain. II. Clinical imaging and treatment. Skeletal Radiol 2010; 39: 837-857

[44] Buijze GA, Ochtman L, Ring D. Management of Scaphoid Nonunion. J. Hand Surg. Am 2012; 37: 1095-1100

[45] Toms AP, Chojnowski A, Cahir JG. Midcarpal instability: a radiological perspective. Skeletal Radiol 2011; 40: 533-541 
[46] Garcia-Elias M. The Non-Dissociative Clunking Wrist: A Personal View. J. Hand Surg (European Vol) 2008; 33: 698-711

[47] Taleisnik J. Classification of carpal instability. Bull. Hosp. Jt. Dis. Orthop. Inst 1984; 44 (2): 511-531

[48] Niacaris T, Ming BW, Lichtman DM. Midcarpal Instability. Hand Clin 2015; 31: 487-493
[49] Youm Y, McMurthy RY, Flatt AE et al. Kinematics of the wrist. I. An experimental study of radial-ulnar deviation and flexion-extension. J. Bone Jt. Surg 1978; 60: 423-431

[50] Nattrass GR, King GJW, McMurtry RY et al. An alternative method for determination of the carpal height ratio. J. Bone Jt. Surg 1994; 76: 88-94 